\title{
The efficiency of indices of richness, evenness and biodiversity in the investigation of species diversity changes (case study: migratory water birds of Parishan international wetland, Fars province, Iran)
}

\begin{abstract}
The species diversity in a region is investigated by the indices (species richness, evenness and biodiversity) and their common methods of measurement (evenness index: Simpson, Camargo and Smith \& Wilson; biodiversity index: Shannon-Wiener, Brillouin and Simpson). It is important to know the suitable index and its measurement method to study species diversity. To analyze the efficiency of the indices and their methods and the relationship between them in this research, the migratory aquatic birds in Parishan wetland was studied as biodiversity is better understood for birds than for any other organisms. Results showed that species richness alone cannot be utilized to estimate the species diversity of the study area. On the other hand, there are dissimilarities between the trends of evenness and biodiversity indices. In order to measure evenness index, there was no difference between Simpson and Camargo methods and their correlation was significantly high but Smith \& Wilson was unequal to them. In biodiversity index, there also was no difference between Shannon-Wiener and Brillouin methods with significantly high correlation but Simpson was unlike them. This research showed that the application of indices of species diversity and their methods of measurement should be employed due to the purpose of experiment.
\end{abstract}

Keywords: Richness index, evenness index, biodiversity index, parishan wetland, correlation
Volume I Issue 2 - 2017

\author{
Goudarzian P, Erfanifard SY \\ College of Agriculture, Shiraz University, Iran
}

Correspondence: Pardis Goudarzian, College of Agriculture, Shiraz University, Esfahan, Iran, Tel 09389123965, Email p.goodarzian1986@gmail.com

Received: July 28, 2017 | Published: August 14, 2017

\section{Introduction}

Wetlands are among the world's most productive environments and one of their best known functions is to provide a habitat for migratory aquatic birds..$^{1-3}$ Wetlands are important habitats that these birds use them for wintering, resting, shelter, and they are also used as a source of drinking water, feeding, and social interactions. On the other hand, wetlands are strongly influenced by human impacts, because they are located where people live, such as nutrient-rich soils for agriculture and silviculture. Human activities can degrade or even destroy wetland habitats, and the health and livelihood of migratory aquatic birds are put at risk..$^{4-6}$ Despite the increase in wetland conservation efforts over the past three decades, ${ }^{1,7}$ substantial losses of wetlands continue. It is not surprising then that many waterbird populations in different parts of the world remain in long-term and considerable decline, since wetland loss and degradation continue to be the main cause for these population changes, probably now being exacerbated by severe and prolonged droughts and other impacts of climate change. All these circumstances determine habitat selection by migrant birds and habitat loss hence is the major threat to them and habitat protection is the most important means of conserving their biodiversity. In Zagros landscapes located in the western Iran, wetlands, as in other dry lands, represent a broad variety of natural resources with environmental, social, and scientific values and play an important role in the maintenance of biological diversity. Despite their great intrinsic values, these ecosystems are suffering a severe pressure caused by human demands for water, agricultural production and habitation leading to the disappearance of many of them.
Migratory waterbirds depend on suitable wetlands and migration success depends on intact migratory routes with the availability of certain key food resources and resting opportunities at these sites. We believe that they are susceptible to changes happened to wetlands and it might affect their habitat preferences for wintering. ${ }^{8,9}$ Being more vulnerable to environmental changes, migratory waterfowls can be a robust bioindicator of wetlands status. These biodiversity indicators are quantifiable environmental factors ${ }^{10}$ that can show how the circumstances vary and help assess the suitable environment for migrating birds induced by human impacts. Responses of migrant waterbirds to the characteristics of natural wetlands influence their richness and diversity. We therefore suggested long-term monitoring of their biodiversity to discover how internationally concerned wetlands have been degraded and what are the consequences of this degradation on migratory birds. One basic approach to quantify biodiversity is to apply the predefined measures i.e. richness, evenness and diversity. ${ }^{11-14}$ Estimating these indices, there are some common methods i.e. Simpson, Camargo and Smith \& Wilson in evenness and Shannon-Wiener, Brillouin and Simpson in biodiversity. ${ }^{3,14,15}$ It is believed that each one of the mentioned criteria may provide meaningful understanding of the wetland's biodiversity changes. The integration of biodiversity monitoring is an essential step in the assessment of the wetland's conditions.

There are some investigations that have studied birds biodiversity. ${ }^{3,4,8,16-18}$ The diversity of aquatic birds was also performed in some wetlands in Iran. ${ }^{19-23}$ The most suitable index and method of biodiversity evaluation is not mentioned in these researches. Also the results of different indices and their methods of measurement 
have not been discussed about waterbirds diversity. The objectives of present research are: 1) to introduce the biodiversity of migrating aquatic birds as a robust bioindicator of wetlands degradation, 2) to validate the efficiency of common biodiversity indices in migratory waterbirds, 3) to compare the results of diversity indices and their methods to choose the suitable one.

\section{Materials and methods}

\section{Study area}

Parishan International wetland (PIW), an Iranian Ramsar Site in Fars Province, is one of the two demonstration sites for the UNDP/GEF Conservation of Iranian Wetlands Project. It lies to the east of Kazeroun City ( $51^{\circ} 47^{\prime} \mathrm{N}$ and $29^{\circ} 30^{\prime} \mathrm{E}$ ) and is part of the Arjan Parishan Protected Area and is recognized by UNESCO as a Biosphere Reserve. The wetland is designated, since 1976, as a Ramsar site and a UNESCO Biosphere Reserve. The surface area of this wetland changes from 2500 to 5200 ha depending on hydrologic conditions..$^{24,25}$

\section{Bird surveys}

It was necessary to count the migratory waterbirds of PIW in each year. This has been performed by Environment Preservation Organization (EPO) during 5 January till 5 February of each year using standardizing survey methodology for wetlands. The 21-year (1989-2009) census of migrating birds was applied in this research.

\section{Data analysis}

The diversity indices i.e. richness, evenness and biodiversity were evaluated for waterbirds diversity applying the most common methods of their estimation mentioned in previous studies. ${ }^{18,26}$

\section{Richness}

Species richness (or the number of species) is currently the most widely used diversity measure. Different methods were suggested by many investigators to measure this index and the number of species (n) as the species richness (s) is the most common method among others. ${ }^{3,27}$

\section{Evenness}

Species evenness (or relative species abundance) in a community is another factor that affects diversity. One of the most frequent methods of evenness measurement is Simpson. ${ }^{15}$ Simpson's evenness index is defined as:

$$
E_{1 / D}=\frac{1 / D}{n}
$$

where D is Simpson's biodiversity index and $\mathrm{n}$ is the number of species. The second general method is Camargo suggested by Camargo (1993). As is the case for Simpson, this method is less sensitive to rare species. Camargo's evenness index is calculated by:

$$
\dot{E}=1-\sum_{n_{1}=1}^{n} \sum_{n_{2}=n_{1}+1}^{n}\left|p_{n_{1}}-p_{n_{2}}\right| / n
$$

where $P_{n}$ is species frequency and $n$ is the number of species. Smith \& Wilson (1996) suggested a new method that is based on species frequency. This method is sensitive to rare and dominant species of the community. It is measured through the equation:

$$
E_{\text {var }}=1-2 / \pi \arctan \left[\sum_{n_{1}=1}^{n}\left(\ln \left(x_{n_{1}}\right)-\sum_{n_{2}=1}^{n}\left(\ln \left(x_{n_{2}}\right)\right) / n\right)^{2} / n\right]
$$

where $n_{1}$ is the number of individuals of the first species, $n_{2}$ is the number of individuals of the second species and $n$ is the number of all individuals in all species.

\section{Biodiversity}

Biodiversity is a combination of richness and evenness. Simpson is the most popular and frequently used biodiversity index. ${ }^{28,29}$ It defines the probability that two equal individuals, selected randomly, belong to different species. This method is measured by:

$$
D=1-\sum_{i=1}^{n} p_{i}^{2}
$$

where $\mathrm{n}$ is the number of species and $\mathrm{p}_{\mathrm{i}}$ is the relative frequency of each species. The other common method of biodiversity measurement is Shannon-Wiener. It estimates the average uncertainty in predicting which species each randomly selected individual belongs to. The following equation is applied:

$$
H^{\prime}=\sum_{i=1}^{n} p_{i} \ln p_{i}
$$

where $n$ is the number of species and $p_{i}$ is the relative frequency of each species. The third method of biodiversity estimation is Brillouin. It is similar to Shannon-Wiener and is applied when random selection of samples is doubtful and is defined as:

$$
H B=1 / n \ln n ! / n_{1} ! n_{2} !
$$

where $n_{1}$ is the number of individuals of the first species, $n_{2}$ is the number of individuals of second species and $\mathrm{n}$ is the number of all individuals in all species.

\section{Correlation tests}

The correlation between these measures was studied by Pearson correlation test. It is then possible to figure out how the indices and methods are related. The statistically significance of the correlation coefficient was evaluated by $t$-test (one-tailed). ${ }^{3,8}$

\section{Results}

There were 91 species in PIW during the study period (1989-2009). The highest and the lowest amounts were observed in 1989 (39,806 birds) and 2009 (200 birds), respectively that showed a decreasing trend (Figure 1). The richness index was at its highest rate in 1994 (57) and the lowest one was observed in 2009 (10) (Figure 2). The results showed that there was no high correlation between richness and biodiversity although it was statistically significant (Table 1). The evenness index of aquatic birds in PIW was the highest in 2009 (0.424) applying Simpson and Camargo but Smith \& Wilson showed that it was the highest in 1999 (0.296) (Fig. 3). The correlation was also significantly high between Simpson and Camargo (0.958) but it was not the case for Smith \& Wilson (Table 1). Comparing the Shannon-Wiener index of biodiversity and the Simpson index of evenness showed contradictory results in the study area (1996-97 and 2008-09) (Figure 3) (Figure 4). 


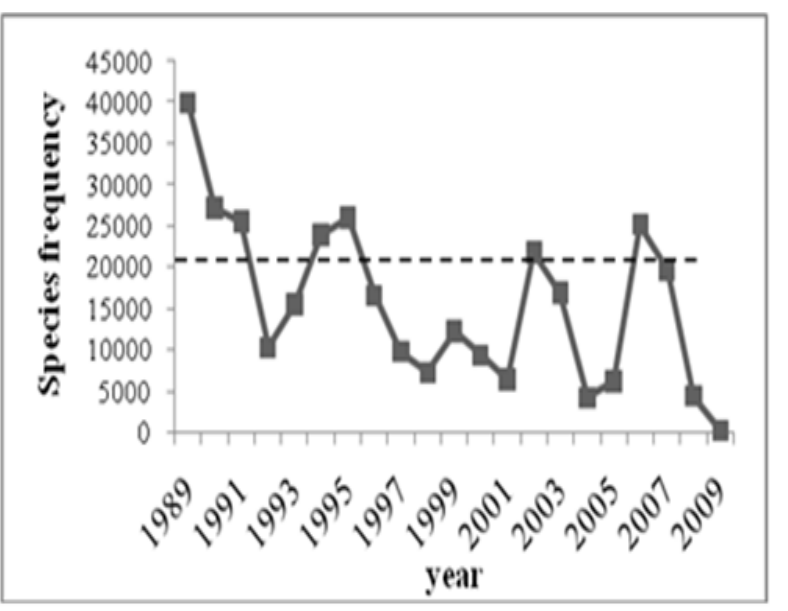

Figure I The species frequency of aquatic birds in PIW from 1989 to 2009.

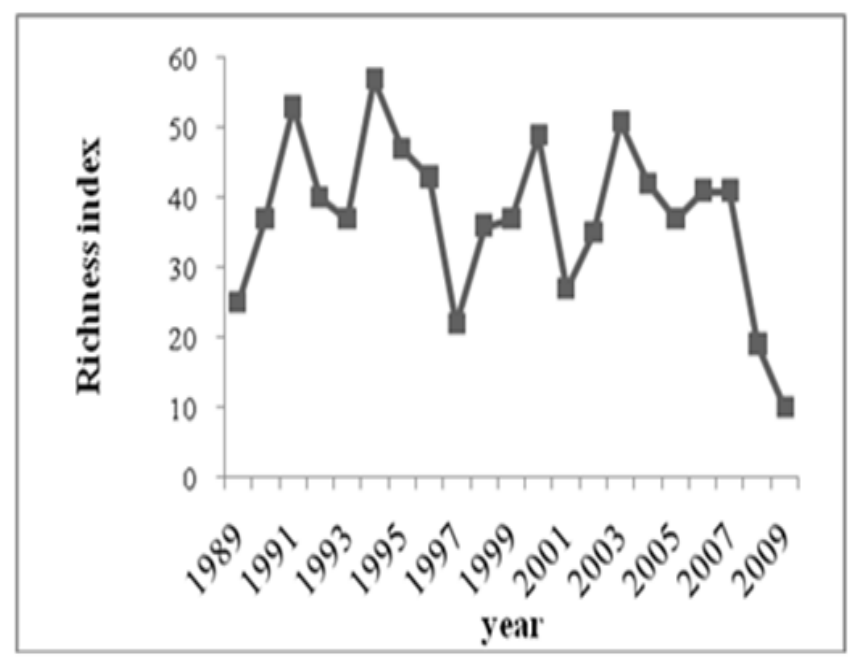

Figure 2 The richness index of aquatic birds in PIW.

\section{Discussion and conclusion}

The richness index was at its highest rate in 1994 (57) and the lowest one was observed in 2009 (10) (Figure 2). The results showed that there was no high correlation between richness and biodiversity although it was statistically significant (Table 1). On the other hand, the trend of richness was opposite of the biodiversity in some years (e.g. 1989-90 and 2005-06). These conflicts were also observed in species frequency and evenness. This relationship was obtained by Alvarez \& Fors. ${ }^{17}$ It is concluded that richness index alone is not suitable enough to investigate the biodiversity of waterbirds in the study area.

The evenness index of aquatic birds in PIW was the highest in 2009 (0.424) applying Simpson and Camargo but Smith \& Wilson showed that it was the highest in 1999 (0.296) (Figure 3). The correlation was also significantly high between Simpson and Camargo (0.958) but it was not the case for Smith \& Wilson (Table 1). So there is no difference between Simpson and Camargo indices of evenness. This result is different from Golshahi et $a .^{23}$ because of the opposite trend between these two methods in his investigation. The changes of evenness and biodiversity were not the same in the migrating birds of PIW. Comparing the Shannon-Wiener index of biodiversity and the Simpson index of evenness showed contradictory results in the study area (1996-97 and 2008-09) (Figure 3) (Figure 4). Although Hvenegaard ${ }^{11}$ deduced that the mentioned indices have the same style in his research. The results proved that different indices of evenness cannot alone be applied to measure the species diversity of migratory aquatic birds. It is suggested to utilize Simpson or Camargo measures if it is necessary to estimate the evenness index.

Beside richness and evenness, the biodiversity of birds is calculated in some researches. Our analyses showed that unlike Simpson index of biodiversity, Shannon-Wiener and Brillouin methods were completely the same (Figure 4). The similar outcomes were accomplished by correlation tests either $(0.999$ correlation coefficient between Shannon-Wiener and Brillouin) (Table 1). This relationship was also shown by Behroozi Rad et al. ${ }^{20}$ and Nabavi et al. ${ }^{21}$
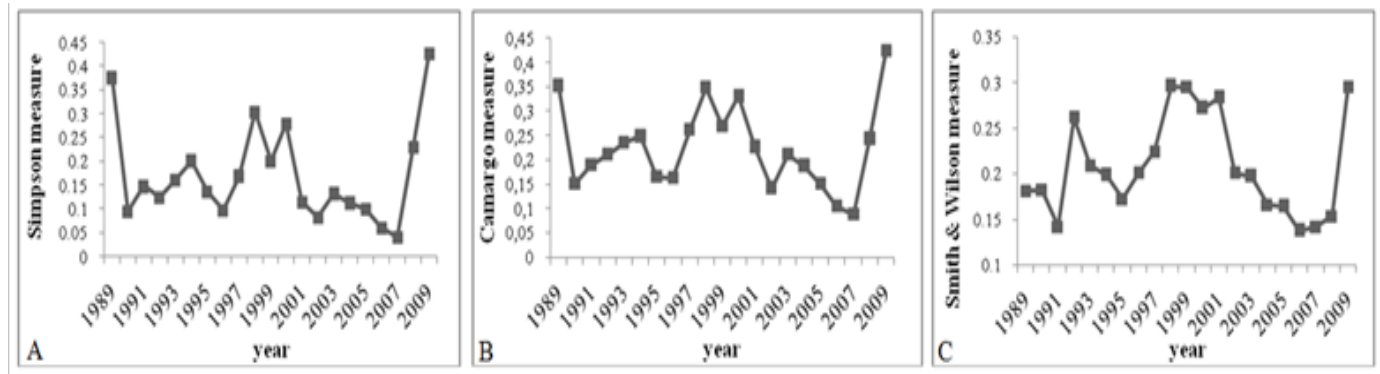

Figure 3 The evenness index of aquatic birds in PIW applying three methods of A) Simpson, B) Camargo and C) Smith \&Wilson
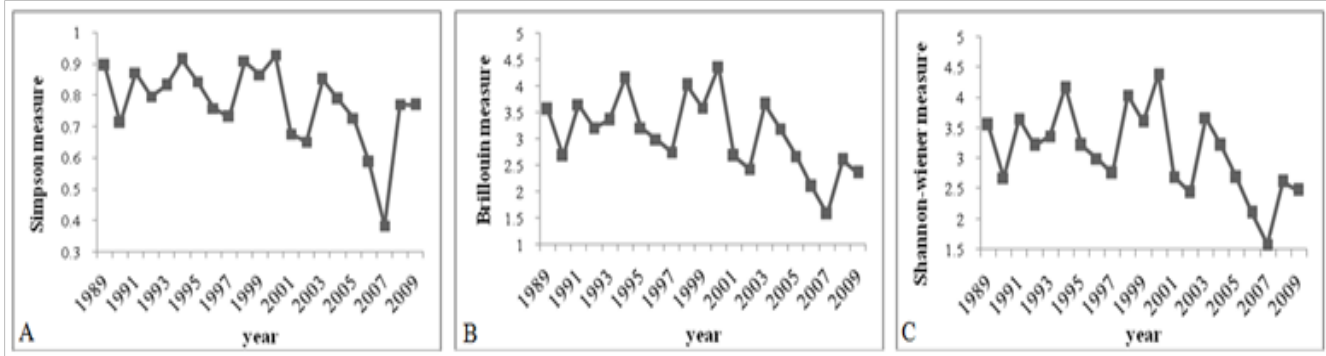

Figure 4 The biodiversity index of aquatic birds in PIW applying three methods of A) Simpson, B) Brillouin and C) Shannon-Wiener. 
Table I Pearson correlation test between different indices and their methods

\begin{tabular}{|c|c|c|c|c|c|c|c|c|}
\hline \multicolumn{2}{|c|}{ Indices and methods } & \multirow[t]{2}{*}{ Richness } & \multicolumn{3}{|l|}{ Evenness } & \multicolumn{3}{|c|}{ Biodiversity } \\
\hline & & & Simpson & Camargo & $\begin{array}{l}\text { Smith \& } \\
\text { wilson }\end{array}$ & Simpson & $\begin{array}{l}\text { Shannon- } \\
\text { wiener }\end{array}$ & Brillouin \\
\hline Richness & & I & $-0.46 I^{*}$ & $-0.447^{*}$ & -0.295 & 0.206 & $0.457^{*}$ & $0.472 *$ \\
\hline \multirow[t]{3}{*}{ Evenness } & Simpson & $-0.46 I^{*}$ & 1 & $0.958 *$ & $0.504 *$ & $0.582 *$ & $0.436 *$ & $0.414 *$ \\
\hline & Camargo & $-0.447^{*}$ & $0.958 * *$ & I & $0.684 * *$ & $0.63 I^{* *}$ & $0.517^{* *}$ & $0.495^{*}$ \\
\hline & Smith \&Wilson & -0.295 & $0.504 * *$ & $0.684 * *$ & I & 0.368 & $0.369 *$ & 0.352 \\
\hline \multirow[t]{3}{*}{ Biodiversity } & Simpson & 0.206 & $0.582 * *$ & $0.63 I^{* *}$ & 0.368 & I & $0.924 * *$ & $0.918^{* *}$ \\
\hline & Shannon-Wiener & $0.457^{*}$ & $0.436^{*}$ & $0.517 * *$ & $0.369 *$ & $0.924 * *$ & I & $0.999 * *$ \\
\hline & Brillouin & $0.472 *$ & $0.414^{*}$ & $0.495^{*}$ & 0.352 & $0.918 * *$ & $0.999 * *$ & 1 \\
\hline
\end{tabular}

Overall, the indices of species diversity (richness, evenness and biodiversity) and their measures should be applied due to the aims of each research. It is necessary to know that the species richness is biased toward rare species while the species evenness is biased toward dominant species. The negative correlation between them in this study proves this relationship. Due to the results, it is recommended to apply a combination of richness, evenness and biodiversity to investigate the species diversity of migrating waterbirds. The results of these indices are not completely the same all the time and it should be taken into consideration while interpreting the species diversity. According to this study, Simpson (or Camargo) index of evenness and ShannonWiener (or Brillouin) index of biodiversity are suggested for future researches on aquatic birds. Finally, the decreasing trend of the species frequency (Figure 1), the richness (Figure 2) and the biodiversity (Figure 4) of migratory birds denotes the degradation of PIW along the 21-year period. It is concluded that long-term monitoring of the biodiversity of migrating aquatic birds is a robust bioindicator of wetlands degradation.

\section{Acknowledgments}

None.

\section{Conflict of interest}

Authors declare there is no conflict of interest.

\section{References}

1. Anonymous. The Ramsar Convention manual, 4th Ed. Ramsar convention secretariat. Switzerland; 2006. p. 118.

2. Bagherzadeh Karimi M, Rohani Rankouhi M. Guide of Recorded wetlands in the Convention. Rouzno press, Tehran, Iran; 2006. p. 183

3. Hvenegaard GT. Validating bird diversity indicators on farmland in eastcentral Alberta, Canada. Ecological Indicators. 2011;11:741-744.

4. Pino J, Roda F, Risa J, et al. Landscape structure and bird species richness: implications for conservation in rural areas between natural parks. Landscape and Urban Planning. 2000;49:35-48.Bellio MG, Kingsford RT, Kotagama SW. Natural versus ratification-wetlands and their waterbirds in Sri Lanka. Biological Conservation. 2009;142:3076-3085.

5. Li D, Chen S, Guan L, et al. Patterns of waterbird community composition across a natural and restored wetland landscape mosaic, Yellow River Delta, China. Estuarine, Coastal and Shelf Science. 2011;91(2):325-332.

6. Boix D, Sala J, Gascon S, et al. Comparative biodiversity of crustaceans and aquatic insects from various water body types in coastal Mediterranean wetlands. Hydrobiologia. 2007;584(1):347-359.
7. St-Louis V, Pidgeon AM, Radeloff VC, et al. High-resolution image texture as a predictor of bird species richness. Remote Sensing of Environment. 2006;105:299-312.

8. Desgranges JL, Ingram J, Drolet B, et al. Modelling wetland bird response towater level changes in the lake Ontario-st Lawrence river hydrosystem. Environmental Monitoring and Assessment. 2006;113(1-3):329-365.

9. Duelli P, Obrists MK. Biodiversity indicators: the choice of values and measures. Agriculture, Ecosystems and Environment. 2003;98:87-98.

10. Abbasi SH, Afsharzadeh S. A review of biodiversity measuring methods in plant coverage of Iran. first national congress on the conversation ecology, Tehran, Iran; 2010. p. 44-51.

11. Andersen AN, Brault A. Exploring a new biodiversity frontier: subterranean ants in northern Australia. Biodivers Conserv 2010;19(9):2741-2750.

12. Feld CK, Sousa JP, Silva PM, et al. Indicators for biodiversity and ecosystem services: towards an improved framework for ecosystems assessment. Biodivers Conserv. 2010;19(10):2895-2919.

13. Hewitt J, Thrush S, Lohrer A, et al. A latent threat to biodiversity: consequences of small-scale heterogeneity loss. Biodivers Conserv. 2010;19(5):1315-1323.

14. Krebs CJ. Ecological methodology. Harper and Row press, New York, USA; 1989. p. 654.

15. Mitchel MS, Rutzmoser SH, Wigley TB, et al. Relationships between avian richness and landscape structure at multiple scales using multiple landscapes. Forest Ecology and Management. 2006;221(1-3):155-169.

16. Alvarez RO, Fors IM. Living in the big city: Effects of urban land-use on bird community structure, diversity, and composition. Landscape and Urban Planning. 2009;90:189-195.

17. Vallejo BM, Aloy AB, Ong PS. The distribution, abundance and diversity of birds in Manila's last green spaces. Landscape.and Urban Planning. 2009;89:75-85.

18. Khaleghizadeh A. Comparative investigation on diversity, density and pattern of aquatic winter birds in Selkeh and Siah-Keshim International wetlands.TMU, Tehran, Iran; 2000. p. 68.

19. Behrouzi RB, Bakhtiari AR, Rostami AK. A monthly survey of biodiversity changes of waterfowls and waders in Selkeh and SiahKeshim (Espand class) international wetlands. Natural Recourses. 2002;55(2):243-260

20. Nabavi M, Behrouzirad B, Yousefian S. Abundance distribution and species diversity of waterfowl of Shadegan wetland. Environmental Studies. 2006;31(38):109-116. 
21. Rahimi S, Tabiee O, Joolaee M. The study on the species diversity of wintering waterfowl and waders of Kaftar wetland in Fars province. Wetland. 2010;1(2):70-80.

22. Golshahi A, Hemami M, Khalilipoor A. The Diversity of Wintering Water and Shore birds in Alagol, Almagol, Ajigol and Gomishan Wetlands. Wetland. 2009;1:18-32.

23. Anonymous. Lake Parishan integrated management plan. UNDP/GEF Conservation of Iranian Wetlands project in corporation with Lake Parishan Organizations and local communities. 2010. p. 46.

24. Jahanifar K. Survey and comparison of State and Private Property Righ Exploitation in Parishan international wetland through opportunity cos method. Middle-East journal of scientific research. 2010;6(3):263-267.
25. Kindt R, Damme PV, Simons AJ. Tree diversity in western Kenya: using profiles to characterise richness and evenness. Biodiversity and Conservation. 2006;15(4):1253-1270.

26. Esmailzadeh A, Hoseini M. The relationship between plant ecological groups and plant biodiversity indices in Afratakhteh Yew (Taxusbaccata L.) reserved area. Environmental Studies. 2007;33(43):21-30.

27. Nagaoka L. Using diversity indices to measure changes in prey choice at the shag river mouth site, southern New Zealand. International Journal of Osteoarchaeology. 2001;11(1-2):101-111.

28. Nagendra H. Opposite trends in response for the Shannon and Simpson indices of landscape diversity. Applied Geography. 2002;22:175-186. 